\title{
Correction: CoNVEX: copy number variation estimation in exome sequencing data using HMM
}

\author{
Kaushalya C Amarasinghe ${ }^{1 *}$, Jason $\mathrm{Li}^{2}$, Saman K Halgamuge ${ }^{1}$ \\ From The Eleventh Asia Pacific Bioinformatics Conference (APBC 2013) \\ Vancouver, Canada. 21-24 January 2013
}

Our proposed method, to detect copy number variations in whole exome sequencing data [1] was published in BMC Bioinformatics as a special issue containing the proceedings of The Eleventh Asia Pacific Bioinformatics Conference (APBC 2013). After the publication, it was brought to our attention that name of our software has a conflict with another software developed by a project carried out at Wellcome Trust Sanger Institute (http://www. uk10k.org/assets/ashg_vijayarangakannan_etal_2012.pdf). We were not aware of this project when we first named our method as "CoNVEX", in mid 2012. Therefore, we would like to thank Dr. P. Vijayarangakannan, one of the developers of the other method, for bringing this to our attention. We would like to mention that, although both software share the same name, they are different in terms of computational methods and types of exome sequencing data used.

To avoid any confusion associated with the software name, we would no longer call our software as "CoNVEX". Our software will be further developed with a new project name, "Aberration Detection in Tumour Exome (ADTEx)".

\section{Acknowledgements}

This article has been published as part of BMC Bioinformatics Volume 14 Supplement 2, 2013: Selected articles from the Eleventh Asia Pacific Bioinformatics Conference (APBC 2013): Bioinformatics. The full contents of the supplement are available online at http://www.biomedcentral.com/ bmcbioinformatics/supplements/14/S2.

\section{Author details}

${ }^{1}$ Department of Mechanical Engineering, University of Melbourne, Parkville, VIC 3010, Australia. ${ }^{2}$ Bioinformatics Core Facility, Peter MacCallum Cancer Centre, VIC 3002, Australia.

Published: 3 June 2013

\footnotetext{
* Correspondence: kca@student.unimelb.edu.au

'Department of Mechanical Engineering, University of Melbourne, Parkville, VIC 3010, Australia

Full list of author information is available at the end of the article
}

Reference

1. Amarasinghe K, Li J, Halgamuge S: CoNVEX: copy number variation estimation in exome sequencing data using HMM. BMC Bioinformatics 2013, 14(Suppl 2):S2.

doi:10.1186/1471-2105-14-S2-S26

Cite this article as: Amarasinghe et al:: Correction: CoNVEX: copy number variation estimation in exome sequencing data using HMM. BMC Bioinformatics 2013 14(Suppl 2):S26.
Submit your next manuscript to BioMed Central and take full advantage of:

- Convenient online submission

- Thorough peer review

- No space constraints or color figure charges

- Immediate publication on acceptance

- Inclusion in PubMed, CAS, Scopus and Google Scholar

- Research which is freely available for redistribution

\section{() Biomed Central}

C Biomed Central

(ㄷ) 2013 Amarasinghe et al.; licensee BioMed Central Ltd. This is an open access article distributed under the terms of the Creative Commons Attribution License (http://creativecommons.org/licenses/by/2.0), which permits unrestricted use, distribution, and reproduction in any medium, provided the original work is properly cited. 